\title{
SEISMIC PERFORMANCE OF SINGLE-STORY PRECAST BUILDINGS: EFFECT OF CLADDING PANELS
}

\section{Marianna ERCOLINO ${ }^{1}$, Gennaro MAGLIULO ${ }^{2}$, Gaetano MANFREDI $^{3}$}

Abstract: In reinforced concrete industrial precast structures one of the most common seismic damage is the collapse of the cladding panels because of the failure of the panel-to-structure connections. This damage is caused by the interaction between the panels and the structures, which is usually neglected in the design approach. The present study aims at investigating this interaction. Nonlinear dynamic analyses are performed on several structural models in order to take into account both the panel-to-structure interaction and the roof diaphragm. According to the analyses results, if the current European single-story precast buildings stock is considered, panels stiffness significantly influences the overall structural behavior under seismic actions and the failure of the connections occurs at very low intensity values. The progressive collapse of the panels is also simulated in order to evaluate the redistribution of seismic demand in the columns during the earthquake. In the final part, fragility curves are evaluated in order to generalize the dynamic analyses results.

Author keywords: precast structures, cladding panels, seismic response, dynamic analyses, incremental dynamic analysis, fragility curves

\section{Introduction}

9 Connection systems are the crucial points in the seismic performance of precast reinforced concrete (RC) structures. During recent earthquakes in Europe (Belleri et al., 2015, Belleri et al., 2014, Magliulo et al., 2014), several existing precast structures showed severe damage at the connections.

2 One of the most common damage was the failure of the external cladding panels; it caused many 3 injuries and casualties as well as significant economic losses due to the interruption of the 4 industrial/commercial activities. The panels failure was caused by the connections fracture and it can be explained by the design approach. Indeed, the cladding panels are commonly considered as

\footnotetext{
${ }^{1}$ Senior Lecturer, University of Greenwich, Email: M.Ercolino@ greenwich.ac.uk

${ }^{2}$ Assistant professor, University of Naples Federico II (corresponding author), E-mail: gmagliul@ unina.it

${ }^{3}$ Full professor, University of Naples Federico II, E-mail: gamanfre@ unina.it
} 
nonstructural elements and the interaction with the structure under seismic loads is neglected.

27 According to Eurocode 8 (CEN, 2005), the panel-to structure connections are dimensioned only for forces in the out-of-plane direction of the panels. These forces are both seismic actions deriving from the panel self-weight and wind actions. However, under dynamic actions the panel-to-structure interaction can occur and the connections could fail since they are carrying forces that were not considered during the design phase, e.g. in-plane actions.

In the last decades several research studies were developed on the panel-to-structure interaction under seismic loads. In these works the effect of the panels was investigated in order to evaluate both the dynamic properties (e.g., frequencies and damping ratios) and the structural seismic performance (e.g., drift ratios, displacement demand). However, most of these research studies concerned some typical U.S. buildings, i.e. steel high-rise buildings, as extensively reported in Hunt and Stojadinovic (2010). In the last years the scientific community recognized the need of a systematic study on the structure-cladding panel interaction in RC precast buildings, typically implemented in Europe for industrial and commercial activities. Recently, an European research project was conducted on this topic: the SAFECLADDING project, aimed at studying the effect of cladding panels on precast industrial buildings. In the framework of this project, a first study was developed by Biondini et al. (2013); in this work the authors investigated the effect of vertical panels by assuming the interaction at the level of the panel-to-panel connections. Since the numerical forces in the connections were too high if the interaction between the panels was considered, the authors proved the efficiency of an innovative dissipative connection between vertical panels. In the framework of the same project, experimental campaigns were performed on some typical panel-to-structure connection systems, in order to assess their seismic performance, e.g. failure modes, strength and deformability (Zoubek et al., 2016). The experimental results were used in order to perform a systematic seismic fragility study, described in Babič and Dolšek (2014). In this research work, the authors performed 3D nonlinear analyses on several precast structures and they defined the fragility curves for twelve industrial precast building classes. These classes were defined by varying the type of non-structural components (vertical panels, horizontal panels and masonry infills), the geometrical configuration, the design approaches and the panel-to-structure connection systems. According to the outcomes of this study, the authors concluded that the effect of non-structural components should be taken into account in both the design and the seismic assessment of such buildings since the overall safety of the structures decreases if these components are considered in the models. In this study the connection models are assumed from the correspondent tested connections and the roof is modeled as flexible in its own plane. Despite the noteworthy effort in the last years, other investigations are necessary in order to delineate more 
general conclusions on the panel influence for precast structures as well as on the design of precast structures with cladding panels. Indeed, during the design phase some simplified assumptions are generally necessary (e.g., flexible or rigid roof hypotheses without modeling the roof elements in the structural models). If the cladding panels have to be considered in the structural analysis, a detailed model of the connections is required (e.g., based on experimental results), which should be generalized by extensive experimental campaigns and/or numerical studies. At this aim, Magliulo et al. (2015) proposed a simplified model of precast structure with cladding panels. In this model the panel-to-structure interaction is assumed at the beam-to-panel connections (vertical panels), the nonstructural elements are considered as elastic elements and the connections are fixed constraints between the structure and the panel. By performing an extensive parametric study, the authors evaluated the first periods of single-story precast buildings by means of linear modal analyses in two limit cases: negligible panels effect (bare structures) and not-negligible panels effect (structures with panels). In this last case, a significant effect of the panels on the structural dynamic behavior was demonstrated and the simplified period formula of Eurocode 8 was compared with the analysis results in order to verify its capability.

The presented study investigates the cladding panel effect on the nonlinear seismic response of a reference precast industrial building. The adopted case-study is a new building, designed according to Eurocodes. The seismic assessment of the structure is performed by means on nonlinear dynamic analyses in OpenSees (McKenna and Fenves, 2013) program. Several structural models are considered by varying the assumptions on both the roof stiffness and the occurrence of panel-tostructure interaction. The results of models with the cladding panels demonstrate the significant effect of the panels on the seismic behavior of these buildings; moreover, they justify the typical connection failure under dynamic actions. In order to improve the reliability of the numerical results, a model with the cladding panels is developed that is able to simulate the panel collapse during the seismic load. If the panels collapse is simulated, the results show a significant difference in the structural response in terms of both connection failure and forces distribution. In the final part of the paper, the seismic vulnerability of the structures is evaluated by taking into account all the above-cited modeling assumptions in order to define general conclusions to lead the designer to choose the approach for such buildings.

\section{Case-study structure}

The investigated case study is a precast industrial building (Figure 1). It consists of precast columns, fixed at the base by means of socket foundation and connected at the top by secondary girders and principal beams in the two horizontal directions. The principal beams support the roof elements. The columns height is equal to $9 \mathrm{~m}(29.5 \mathrm{ft})$; the width of the six X-bays is $12 \mathrm{~m}(39.4 \mathrm{ft})$ 
and the width of the two Z-bays is $19 \mathrm{~m}(62.3 \mathrm{ft})$. The horizontal elements are designed by considering only the vertical loads (permanent and variable loads); they consist of prestressed TT roof elements, prestressed principal beams in the transversal direction ( $\mathrm{Z}$ direction in Figure 1$)$ and secondary girders in the longitudinal direction ( $\mathrm{X}$ direction in Figure 1). Dowel connections are usually installed between the principal beam and the columns as well as between the roof elements and the principal beams. The girder-to-column connection usually consists of bolted steel joints. Vertical reinforced concrete precast cladding panels are connected to beams or girders, as described in section "Model with cladding panels".

The columns are designed according to Eurocode 8 (CEN, 2005), assuming a peak ground acceleration equal to $0.168 \mathrm{~g}$ (return period of 475 years and soil type "B") and ductility class "DCH". The behavior factor is equal to 4.5, as indicated in Eurocode 8. The columns have squareshaped cross-sections $(80 \mathrm{~cm} \times 80 \mathrm{~cm}-31.5$ inches x 31.5 inches) reinforced with $22 \mathrm{~mm}$ diameter longitudinal bars $(\rho=1.66 \%)$ and $10 \mathrm{~mm}$ ( 0.39 inches $)$ diameter stirrups, $12.5 \mathrm{~cm}$ (4.9 inches) spaced. The concrete cubic characteristic strength is equal to $55 \mathrm{~N} / \mathrm{mm}^{2}$ with an elastic modulus equal to $36283 \mathrm{~N} / \mathrm{mm}^{2}\left(757786 \mathrm{kips} / \mathrm{ft}^{2}\right)$, computed according to Eurocode 2 (CEN, 2004). The reinforcement steel has a yielding characteristic strength equal to $450 \mathrm{~N} / \mathrm{mm}^{2}\left(9398 \mathrm{kips} / \mathrm{ft}^{2}\right)$.

The total seismic weight is equal to about $6.7 \mathrm{kN} / \mathrm{m}^{2}\left(140 \mathrm{kips} / \mathrm{ft}^{2}\right)$. The design is performed, as usually happens, assuming bare structure and rigid diaphragm.

The design fundamental periods along the two horizontal directions of the designed structure are equal to $1.2 \mathrm{sec}$.

\section{Nonlinear models}

Nonlinear dynamic analyses are performed in OpenSees (McKenna et al., 2013) software on six structural models by taking into account P- $\Delta$ effects. In order to investigate the panel effect, three models are defined: the bare structure and two different models for the building with cladding panels. Moreover, the three models are investigated by assuming two different hypotheses: either the rigid roof in its own plane hypothesis (RF) or the flexible roof (FR) hypothesis. In the former case, the seismic mass of the structures is concentrated in the mass barycenter and the roof is modelled as a rigid body in its own plane. In the latter case, the masses are concentrated at the columns top and no constraints are considered for the roof. In the model with the simulated collapse, the mass of the panels is concentrated in the beam-to-panel connection points in order to remove such mass if the panel collapses during the dynamic analysis.

Concerning the connections between the structural elements, the beam-to-column connections are dowel systems and they can be assumed as hinges. Therefore, the columns carry the horizontal seismic actions and the horizontal elements sustain only the vertical loads. 
128 The fundamental periods along the two horizontal directions of the six structural models are 129 reported in Table 1. It is worth noting that the periods of the bare model are larger than the 130 corresponding periods of the design model, because the secant stiffness to the yielding point of the 131 nonlinear bare model is lower than the assumed elastic stiffness of the design model.

\section{Bare model}

133 In the bare model (BM) the panel-to-structure interaction is neglected; the model consists of 134 columns, girders and principal beams. This assumption is the common modeling approach adopted 135 for precast structures: the panels do not take part to the global structural response under seismic 136 actions.

137 The nonlinear response of the structure is concentrated at the columns base by means of a lumped 138 plasticity approach and the horizontal elements are assumed elastic one-dimensional elements. A 139 tri-linear moment-rotation envelope is assigned to the plastic hinge, consisting of three 140 characteristic points: yielding, capping and post-capping points. The envelope points are assumed 141 according to Fischinger et al. (2008). The yield drift is calculated according to the formula proposed 142 by Fardis and Biskinis (2003):

$$
\theta_{y}=\phi_{y} \cdot L_{s} / 3+0.00275+a_{s l} \cdot \frac{\varepsilon_{y}}{d-d^{\prime}} \cdot \frac{0.2 \cdot d_{b} \cdot f_{y}}{\sqrt{f_{c}}}
$$

The yield curvature $\left(\phi_{\mathrm{y}}\right)$ is evaluated according to the bi-linearization of the moment-curvature envelope, obtained by a fiber analysis of the column cross-section. In the fiber analysis three types of fibers are considered in the cross-section: the unconfined concrete fibers in the concrete cover; the concrete confined fibers (Mander et al., 1988) in the concrete core and the steel fibers of the reinforcing bars. The median values of both the concrete compressive strength $\left(f_{c}=53 \mathrm{~N} / \mathrm{mm}^{2}-\right.$ $\left.1107 \mathrm{kips} / \mathrm{ft}^{2}\right)$ and the steel yielding strength $\left(\mathrm{f}_{\mathrm{y}}=530 \mathrm{~N} / \mathrm{mm}^{2}-11069 \mathrm{kips} / \mathrm{ft}^{2}\right)$ are defined according to Eurocode 2 (CEN, 2004). The slip coefficient $\left(\mathrm{a}_{\mathrm{sl}}\right)$ is assumed equal to 1 and the term (d-d') is 151 evaluated as the distance between the tension and compression reinforcement. According to the 152 structural scheme, the shear span $\left(\mathrm{L}_{\mathrm{s}}\right)$ is equal to the height of the column. In Eq. (1) the $\varepsilon_{\mathrm{y}}$ is the 153 yielding strain of the reinforcement $(0.21 \%)$ and $\mathrm{d}_{\mathrm{b}}$ is the diameter of the longitudinal reinforcement 154 (22mm -0.87 inches).

155 The capping and post-capping rotations are evaluated according to Haselton (2006):

$$
\theta_{\text {cap }}=0.12 \cdot\left(1+0.4 \cdot a_{s l}\right) \cdot 0.2^{v} \cdot\left(0.02+40 \cdot \rho_{\text {sh }}\right)^{0.52} \cdot 0.56^{0.01 f_{c}} \cdot 2.37^{10.0 \rho}
$$

$$
\theta_{p c}=0.76 \cdot 0.031^{v} \cdot\left(0.02+40 \cdot \rho_{s h}\right)^{1.02} \leq 0.1
$$


158 In Equations (2) and (3) $v$ is the normalized axial force, $\rho_{\mathrm{sh}}$ is the transverse reinforcement ratio and $159 \rho$ is the longitudinal reinforcement ratio. Given the yielding moment $\left(\mathrm{M}_{\mathrm{y}}\right)$ by the bi-linearization of 160 the moment-curvature curve, the capping moment $\left(\mathrm{M}_{\mathrm{c}}\right)$ is determined as:$$
M_{c} / M_{y}=1.25 \cdot 0.89^{v} \cdot 0.91^{0.01 \cdot f_{c}}
$$

162 The energy dissipation capacity of the plastic hinge is taken into account by the factor $\lambda$ (Eq. (5)), 163 according to Ibarra et al. (2005).

$$
\lambda=127.2 \cdot 0.19^{v} \cdot 0.24^{s / d} \cdot 0.595^{V_{p} / V_{n}} \cdot 4.25^{\rho_{s h, e f f}}
$$

In Eq. (5) $s / d$ is the ratio between the stirrup spacing $(12.5 \mathrm{~cm}-4.9$ inches) and column depth (80cm - 31.5 inches); $V_{p} / V_{n}$ is the ratio between the shear at flexural yielding and the shear strength; and $\rho_{\text {sh,eff }}$ is the effective ratio of transversal reinforcement.

Figure 2 shows the envelopes of the three adopted plastic hinges, corresponding to columns characterized by different values of the axial force: A) internal columns (gray marker in Figure 2b), B) perimetral columns (blue marker in Figure 2b) and C) corner columns (black marker in Figure $2 b)$. This terminology and the colors in Figure $2 \mathrm{~b}$ are adopted in the following section in order to individuate the columns in the structure.

\section{Model with cladding panels}

175 In the Model With Panels (MWP) the cladding panels are introduced in order to take into account their interaction with the structure. The structural elements (columns, girders and beams) are modelled as in the BM. In this study, the vertical panels are investigated and the connection at the top is shown in Figure 3. The connection at the bottom of the panel may consist of clip-panel beams

179 equipped with a fork or welded/bolted metal anchors. The adopted model does not consider the 180 uplift capacity of the panel at the bottom. Each panel consists of an elastic 2D frame (Figure 4) and 181 it is connected at the top to the structure (beam) by means of fixed constraints that avoid the panel182 to-structure relative displacement (Magliulo et al., 2015), as often shown during recent earthquakes 183 (Magliulo et al., 2014). The influence of a more detailed model of the panel-to-structure connection 184 will be investigated by the authors in a future research study. Preliminary studies on a single bay 185 structure show that the assumption of rigid connection causes an underestimation of the collapse 186 fragility. 


\section{Model with progressive collapse}

188 In order to simulate the panel collapse, a model (MR) is introduced in OpenSees. This model 189 simulates the panel collapse by means of the "Removal" command (Talaat and Mosalam, 2009).

190 Such a model can be used in order to achieve three main purposes:

i) the evaluation of the real forces at the base of the structural elements during an earthquake;

ii) the justification of the recorded damage in the structural elements due to a seismic event after the collapse of the cladding panels;

iii) the vulnerability assessment of precast single-story structures.

The "Removal" command allows removing from the structural model the cladding panels that achieve the maximum strength in the connection system during the nonlinear dynamic analysis, i.e. once the collapse of the connection is achieved, the analysis of the structure continues without the corresponding panel. In this study, only the shear failure of the connector is considered (Figure 3). Each panel is characterized by two connections with the structure at the top and for each connection a limit domain is defined in terms of displacements in the two horizontal directions. For the out of the plane actions, a very large limit displacement is assumed; on the contrary, for the in-plane direction the limit displacement is evaluated according to the shear strength of the connector. These assumptions are justified by the design approach, typically adopted for panel-to-structure connection in precast buildings (see "Introduction").

\section{Input}

207 Bi-directional nonlinear dynamic analyses are performed with both the components of 7 natural 208 seismic events (CEN, 2005). In Table 2 the main parameters of the selected natural earthquakes are 209 reported in terms of: earthquake ID, name of the real event, date of the event, magnitude, peak 210 ground acceleration in horizontal $\mathrm{X}$ and $\mathrm{Y}$ direction and type of soil according to the EC8 211 categories. The records selection was performed by the software REXEL (Iervolino et al., 2010) in 212 order to match the design elastic spectrum of the considered site with all the 14 records (see Section 213 Case-study structure). Figure 5 shows the comparison between the mean spectrum of the selected 214 records and the design spectrum at a return period of 475 years; in this figure the spectra of the 215 records are reported for the two horizontal components, corresponding to the $\mathrm{X}$ (solid lines) and $\mathrm{Z}$ 216 (dashed lines) directions in this study. The dispersion of the spectral acceleration for the selected 217 ground motions is justified by the need of ensuring the spectrum compatibility for a wide range of 218 periods. Such a need is required to cover both bare structures and structures with cladding panels 219 (Magliulo et al., 2015). 


\section{Nonlinear analyses results}

221 The seismic response of precast structures is investigated by means of nonlinear dynamic analyses 222 in OpenSees, considering the above-described structural models. In order to simplify the discussion about the results, Table 3 shows an overview of the adopted structural models and it introduces the corresponding symbols adopted in the following.

The structural safety is investigated for the Near Collapse Limit State (NC LS). It is assumed to be achieved when $20 \%$ decay of the maximum strength occurs in the first plastic hinge (Fischinger et al., 2008). According to this criterion, the rotational capacity of the plastic hinges are equal to the following values: 1) 0.0850 for internal columns, 2) 0.0768 for perimetral columns and 3) 0.0785 for corner columns. In the model with cladding panels, the safety of the connections is also verified in terms of shear strength of the connector.

\section{Bare models}

232 This section shows the results of the nonlinear dynamic analyses on the bare models. The results of 233 the bare model with rigid roof (BM-RR) are shown in Figure 6; the moment-rotation envelopes of 234 all the columns of the structure are reported around the Z (Figure 6a) and X (Figure 6b) directions, 235 for all the seismic events: for each type of column (perimetral, internal and corner), the moment236 rotation diagram with the maximum rotation is shown. Around both the directions the columns have 237 an elastic response (i.e., the maximum rotation is lower than the assumed yielding rotation) under 238 all the seismic ground motions; however, around $\mathrm{X}$ direction the columns reach the capping rotation 239 for one record ( $\mathrm{ID}=535)$. This result is justified by the large spectral acceleration (Figure 5b) of this 240 seismic event at the period of the structure $(1.60 \mathrm{sec})$. According to the adopted criterion, the 241 structure is safe with respect to the NC LS for all the records.

242 The recorded elastic response demonstrates a significant overstrength of the considered benchmark 243 structure. This overstrength is caused by several reasons, such as the difference between the 244 stiffness of the structures assumed in the design phase and in the dynamic analysis and the 245 difference between the medium and the design values of the material mechanical characteristics. 246 For instance, the yielding force assumed in the nonlinear analysis seismic force of each column is 247 twice the design seismic force of each column. It is interesting to note that this overstrength 248 occurred besides some design aspects: 1) the assumed high value of the behavior factor ( $\mathrm{q}=4.5)$ and

249 2) the percentage of longitudinal reinforcement that is higher than the minimum percentage required 250 by the code $(\rho=1.0 \%)$. According to these two considerations, the overstrength of the structure 251 should not be high and an inelastic behavior would be expected under a set of earthquakes matching 252 the elastic design spectrum. This conclusion on the seismic safety/overstrength of the precast 
structures should be validated by taking into account also the variability in the seismic action and 254 materials (Fischinger et al., 2009).

255 If the flexible roof is considered in the bare model (BM-FR), the response is still elastic for the most of the records (Figure 7). However, the rotational demand increases in both perimetral and internal columns due to the higher value of relevant masses. It is worth highlighting the distribution of seismic demand in the structural frames. Figure 8 shows the demand/capacity ratios in terms of rotations for two external frames around $\mathrm{X}$ and $\mathrm{Z}$ direction. The markers are reported for all the 260 adopted records. The different seismic demand on the columns as well as on the frames 261 demonstrates the absence of the rigid diaphragm; in this case, the distribution of seismic demand can significantly change throughout the columns and it can lead to a low ductile behavior of the overall structure. However, the NC LS is not attained, since the median value (red lines) of the demand/capacity ratios is lower than one. The results in the other frames and in $\mathrm{Z}$ direction are not showed for the sake of brevity.

\section{Structures with panels}

267 Nonlinear dynamic analyses are performed on the models with cladding panels (MWP) with the 268 same set of records. The results are presented in terms of distribution of forces in the structural 269 elements and in the connection system with the rigid (RR) and the deformable roof (FR) 270 hypotheses.

271 Figure 9 shows the moment-rotation curve around $\mathrm{X}$ and $\mathrm{Z}$ direction of the columns for the MWP272 RR: the behavior is elastic and the seismic demand in the columns is very low because of the high 273 stiffness of the cladding panels. If the flexible roof is assumed (MWP-FR), the seismic demand in 274 the columns significantly increases and the behavior is quite similar to the BM-FR (Figure 10). In 275 the case of the flexible roof the stiffness of the panels does not influence the seismic demand in the 276 columns.

277 In order to assess the seismic safety of the panel-to-structure connections, the shear demands are compared to the shear strength of a typical connection. The design of this connection is performed according to the above-described design approach: the seismic design forces are evaluated by considering only the weight of the panel and they are applied in the out of plane direction. Figure 11

281 shows the comparison between the demand from the analysis and the shear strength of the 282 connection for the MWP-RR. In particular, in this figure the markers indicate the demand/capacity 283 ratios in terms of shear of the connector (CEN, 2005) in the panel direction (Figure 11a in $\mathrm{X}$ 284 direction and Figure $11 \mathrm{~b}$ in $\mathrm{Z}$ direction) for each record and for the panels in one frame. In both the directions, the shear strength of the connector is smaller than the seismic forces in the connection. 
286 If the deformable roof is assumed (MWP-FR), the seismic forces in the panel-to-structure 287 connections significantly decrease (Figure 12). This result agrees with the above-presented 288 moment-rotation curves and it is related to the floor in plane deformability: larger forces are 289 recorded in the internal frames because of their larger relevant seismic masses.

290 The results of the nonlinear dynamic analyses justify the widespread failures of cladding panels 291 during some recent earthquakes in Europe. In both the models (i.e., RR and FR) the large stiffness 292 of these nonstructural components causes a significant reduction of the seismic forces in the 293 structural elements (columns) as well as large forces at the panel-to-structure connections. The 294 magnitude of these forces is significantly larger than the strength of the connection, i.e. the shear strength of the connector in the in-plane direction of the panel.

\section{Progressive collapse}

297 The results of the nonlinear dynamic analyses have demonstrated the vulnerability of the panel-tostructure connections if the panels interact with the structure under seismic actions. The low demand/capacity ratios justify the collapse of the panels in the early steps of a seismic record, i.e. also for very low values of acceleration. During the time-history, the collapse of the panels leads to

301 a change of the stiffness distribution in the structures (i.e., change in the dynamic properties) as well 302 as a different seismic demand in the structural elements (columns). In order to investigate such a 303 behavior, nonlinear dynamic analyses are performed on MR-RR and on MR-FR.

304 Figure 13 shows the model capability by reporting two steps of one nonlinear dynamic analysis on MR-RR: in the first steps few panels have collapsed (Figure 13a); whereas in the final step the most of the panels have collapsed under the seismic records (Figure 13b). Figure 14 shows the momentrotation curves around the two horizontal directions for MR-RR: the structure has an elastic response under all the adopted records; however, the forces increase with respect to the model with cladding panels (MWP-RR, see Figure 9). For instance, in this model the yielding rotation is achieved around $\mathrm{X}$ direction for record ID=575.

If the deformable roof is considered (RM-FR) the following conclusions can be drawn by means of the moment-rotation curves in Figure 15.

- Around X direction, the columns experience rotations that are similar to the results in the MWP-FR. In this model the distribution of the seismic demand is influenced by the mass distribution: the internal columns are bearing larger forces than the external ones in both the models. However, the demand on the corner columns increases because of the collapse of the panels during the analysis (Figure 16a). 
- Around $\mathrm{Z}$ direction, the maximum recorded rotations in the $\mathrm{RM}$ are larger than the maximum values in the MWP for the corner columns. The collapse of the panels during the analysis causes an irregular distribution of masses and stiffness in the structure and, therefore, torsional modes can significantly influence the seismic demand in the columns.

- For some records (n.535 and n.196) the rotations around Z direction are significantly larger than in the MWP-FR. In the case of the removal model the collapse of some of the panels causes large changes of the fundamental periods. At the beginning of the analysis, the periods are equal to the model with cladding panels (MWP, see Table 1) as well as the seismic demand. Whereas during the analysis the period increases due to the reduction of the structural stiffness (periods close to the ones of the model BM) and the seismic demand increases for the earthquakes n.535 and n.196 (Figure 5). Figure 16 shows a clear comparison between the results of the analyses on the two models for corner columns around $\mathrm{Z}$ direction.

- A very similar conclusion can be stated by comparing the results of the RM-FR (Figure 15) and the results of the BM-FR (Figure 7). The behavior of the RM is very similar to the BM because of the panels collapse in the early steps of the time-histories. For some records the smaller rotations in the BM can be justified because the values of the spectral acceleration at $\mathrm{T}=1.6 \mathrm{sec}$ (e.g., at the period of the $\mathrm{BM}$ ) are lower than the values of the spectral acceleration at the periods of the RM (in the range 0.5-1.0sec).

341 A seismic risk study is performed on the investigated benchmark structure in order to define the 342 fragility curves for different structural modeling assumptions. The fragility curves are defined for predicting the probability of exceeding a certain level of performance in the structure. In this study,

344 the global collapse limit state of the structure is considered, i.e. the condition in which a structural system is unable to support vertical loads when subjected to seismic excitation.

Incremental dynamic analyses

347 In order to evaluate the limit state capacity of the structure, incremental dynamic analyses (IDA) are 348 performed (Vamvatsikos and Cornell, 2002). The IDA curves are defined by adopting as Intensity 349 Measure (IM) the peak ground acceleration and as Damage Measure (DM) the roof displacement. 350 The adopted DM is evaluated as the square-root-sum-of-squares of the instantaneous drifts in the two principal directions (Vamvatsikos, 2006, Wen and Song, 2003) 
352 In order to assess the global collapse performance in the structure the IM-based rule is adopted: it 353 defines a single point on each IDA curve that corresponds to the achievement of the global collapse 354 limit state. In particular, in this work the collapse criterion is defined by the achievement of a stiffness equal to $20 \%$ of the elastic one (FEMA, 2000). This criterion corresponds to consider the flattening of the curve as an indicator of the dynamic instability, i.e. an indicator of collapse (Fischinger et al., 2009). In the case of the models with cladding panels (MWP), the collapse of the structure can be also achieved if the panels fail, i.e. the seismic demand in the panel-to-structure connections achieves the shear strength of the connector.

360 The nonlinear analyses are performed with a set of twenty-two ground motion record pairs from 361 sites located greater than or equal to $10 \mathrm{~km}$ from fault rupture, referred to as the "Far-Field" in 362 FEMA (2008). The record set includes records from all large-magnitude events in the PEER NGA 363 database (PEER, 2006). Figure 17 shows the spectra of the adopted records, scaled to PGA=1g.

\section{Results}

365 In this section the results of the seismic risk study are presented for all the considered models (bare,

366 with cladding and with removal) and with the two hypotheses on the roof stiffness (rigid and 367 flexible behavior). The considered IM is the peak ground acceleration.

368 Figure 18 and Figure 19 show the IDA curves evaluated for the BM-RR and the BM-FR, 369 respectively. In the same figure the lognormal distribution of the collapse IMs is also reported (red area). The mean value of the peak ground acceleration at the collapse lightly change in the two models; therefore, the fragility curves for the two modeling approaches are similar (Figure 20).

372 The incremental dynamic analyses are also performed on the models MWP-RR and MWP-FR. In 373 the following the results are reported in terms of IDA curve and PDF distribution (Figure 21 and 374 Figure 22). For all the records, the collapse corresponds to the attainment of the shear strength in 375 the connection system, i.e. the shear failure of the connector occurs before the global collapse of the structure. The results highlight the effect of the panels on the seismic risk of the considered precast structure. If the deformable roof is considered the mean peak ground acceleration at the global collapse is significantly larger than in the rigid roof case (Figure 22). This evidence confirms the effect of the mass distribution to the response of the structure: the external frame are carrying 380 smaller forces because of the smaller mass. Figure 23 shows the fragility curves for the structures 381 with cladding panels: the hypothesis on the roof behavior significantly influences the safety of the structure as well as the correspondent seismic risk. The failure criterion in the structures with cladding panels corresponds to the failure of the first panel connection. In this case, the failure of 
for the human life. The results of this analysis can highlight the significant seismic vulnerability of 386 the panel connections.

387 If the collapse of the panels is simulated in the models (RM-RR and RM-FR), the IDA curves are showed in Figure 24 and in Figure 25. The failure criterion is defined at the failure of the columns at the base (dynamic instability). In this case the mean collapse IM is very similar to the values of the bare modes. Figure 26 shows the fragility curves for these structural models. The median value of the IM at collapse in the removal models (1.42g and $1 \mathrm{~g}$ for RR and FR, respectively) is more similar to the values of the corresponding bare models $(1.75 \mathrm{~g}$ and $1.47 \mathrm{~g}$ for $\mathrm{RR}$ and FR, respectively) than to the values of the models with cladding panels $(0.006 \mathrm{~g}$ and $0.0235 \mathrm{~g}$ for $\mathrm{RR}$ and

394 FR, respectively). The collapse of the panels occurs in the very early stage of the seismic records due to the low shear strength of the connectors; during the transient part of the input the structure is behaving like a bare system. It is worth to highlight that the bare models are not on the safe side in the evaluation of the collapse IM of this structure. The results of the two models (BM and RM) can be compared in order to justify the typical modelling assumption of neglecting the presence of cladding panels during both the design and safety assessment phases.

The values of the collapse peak ground acceleration are quite larger than the values found in Dolsek et al. (2016): this evidence can be justified by some reasons, such as: 1) the investigated buildings are designed for different building codes; 2) in the work by Dolsek et al. (2016) the collapse of the structure could be achieved by the failure of the dowel connections between the columns and the beams; on the contrary, in the presented paper a strong connection is assumed.

\section{Conclusions}

406 This work aims at defining the effect of the cladding panels on the seismic response of RC singlestory precast structures. Such effect is evaluated by comparing the results of nonlinear dynamic analyses on six structural models, i.e. by neglecting the interaction between the panel and the structure (bare models) and by modeling the panel-to-structure interaction; in this last case two conditions are taken into account: panel-to-structure interaction staying till the analysis end (models

411 with cladding panels) and progressive panel collapse simulation (removal models). For each model 412 both the rigid and the flexible roof in its own plane hypotheses are considered.

413 The results of the analyses on the bare structures highlight some main conclusions.

414 - The effect of the rigid roof is negligible; however, the seismic performance gets worse if the 415 flexible roof is considered, because the seismic demand is not uniformly distributed in the structural elements.

417 - The overstrength of the structure leads to an elastic behavior under seismic actions and it is mainly caused by the design assumptions in terms of stiffness and material strength. 
In the case of the model with cladding panels, the following conclusions can be drawn.

- The structural performance significantly changes with respect to the bare model if the roof is rigid. In this case, the large stiffness of the panels causes a low demand on the structural elements as well as a significant change in the dynamic properties of the structures.

- In the case of the model with panels and rigid roof, the large forces at the panel-to-structure connections justify the early collapse of the connections during the seismic events. The demand is much larger than the shear strength of the connection in the direction of the panel. The assumption of these connections as rigid constraints under dynamic actions is justified by their behavior observed during recent earthquakes.

- If the model with cladding panels provides the deformable roof, the seismic response of the structures changes as well as the seismic demand at the panel-to-structure connections. The seismic demand on the internal columns increases since the seismic forces distribution is based on the seismic masses rather than on the stiffness of the structural elements. For the same reason, the seismic demand on the connections of the panels decreases.

The analyses on the model with panels demonstrate that the panel-to-structure connections fail in the very early stages of the seismic input (low intensity seismic level). In order to investigate the real behavior of the structures during an earthquake, a novel model is developed (removal model). This model allows recording the redistribution of the forces during a time-history in all the structural elements by simulating the progressive collapse of the panels. The results of the nonlinear dynamic analyses demonstrate that the forces in the columns increase as the panels fail and the overall behavior of the structure is very similar to the behavior of the bare structures. This model might simulate the failure of precast structures, occurred during some seismic events after the collapse of the panels.

In the final part, a seismic risk study is performed in order to define the fragility curves of all the investigated modeling approaches.

- If the flexibility of the roof is considered, the mean peak ground acceleration values lightly decreases at the collapse because of the irregular distribution of the seismic demand in the structural elements. However, in both the bare models, the large values of the mean peak ground acceleration highlight the overstrength of the structure.

- If the panel-to-structure interaction is considered, the failure of the structures occurs for very low values of the peak ground acceleration for both the models with cladding panels. The results are significantly influenced by the assumption on the failure criteria: for all the records the failure is achieved at the collapse of the panel connection. If the roof is rigid in its own plane, the peak ground acceleration at the collapse is very low. 
- If the progressive collapse of the panels is simulated, the fragility analysis gives results similar to the bare model. This evidence demonstrates that the panel-to-structure connections fail for very low seismic intensities (early stages of the seismic event); in this case, the structural behavior is not significantly affected by the panels. However, the overall behavior of the bare model does not predict a safe-sided behavior: the collapse of the bare structure occurs for a seismic intensity that is larger (20\% for rigid roof and $50 \%$ for flexible roof) than the value with the panel progressive collapse.

The influence of a more detailed model of the panel-to-structure connection will be investigated by the authors in a future research study. It should be underlined that the above presented conclusions and results are limited to one-story precast buildings with strong connection systems.

\section{Acknowledgments}

This research was partially funded by the Italian Department of Civil Protection within the national project DPC-ReLUIS 2015 Cemento armato WP2. The passionate support of Eng. Simona Lubrano Lavadera to the execution of the analyses is gratefully acknowledged. The authors would like to thank two anonymous Reviewers for their valuable comments.

\section{References}

Babič, A., and Dolšek, M. "The impact of structural components on fragility curves of single-storey industrial precast structures." Proc., Second European conference on earthquake engineering and seismology, Istanbul, Turkey.

Belleri, A., Brunesi, E., Nascimbene, R., Pagani, M., and Riva, P. (2015). "Seismic Performance of Precast Industrial Facilities Following Major Earthquakes in the Italian Territory." Journal of Performance of Constructed Facilities, 29(5), 04014135.

Belleri, A., Torquati, M., and Riva, P. (2014). "Seismic performance of ductile connections between precast beams and roof elements." Mag Concrete Res, 66, 553-562.

Biondini, F., Dal Lago, B., and Toniolo, G. (2013). "Role of wall panel connections on the seismic performance of precast structures." B Earthq Eng, 11(4), 1061-1081.

CEN (2005). "Design of steel structures. Part 1-8: Design of joints." Eurocode 3, Brussels.

CEN (2005). "Design of structures for earthquake resistance, part 1." Eurocode 8, Brussels. 
482 CEN (2004) "Eurocode 2: Design of concrete structures - Part 1-1: General rules and rules for 483 buildings." Eurocode 2, Brussels.

484 Fardis, M. N., and Biskinis, D. (2003). "Deformation capacity of RC members, as controlled by 485 flexure or shear." International Symposium on Performance-based Engineering for Earthquake 486 Resistant Structures, University of Tokyo.

487 FEMA (2000). "Recommended seismic design criteria for new steel- moment frame buildings." 488 Federal Emergency Management Agency, Washington.

489 FEMA (2008). "ATC-63 Project Report: Quantification of Building Seismic Performance Factors." 490 Federal Emergency Management Agency, Washington.

491 Fischinger, M., Kramar, M., and Isakovic, T. (2009). "Seismic safety of prefabricated reinforced492 concrete halls - analytical study." Gradev, 61(11), 1039-1045.

493 Fischinger, M., Kramar, M., and Isaković, T. (2008). "Cyclic response of slender RC columns 494 typical of precast industrial buildings." Bull. Earthq. Eng., 6(3), 519-534.

495 Haselton, C. (2006). Assessing Seismic Collapse Safety of Modern Reinforced Concrete Moment496 Frame Buildings, PEER Report, Department of Civil Engineering California State University, 497 Chico.

498 Hunt, P. J., and Stojadinovic, B. (2010). Seismic Performance Assessment and Probabilistic Repair 499 Cost Analysis of Precast Concrete Cladding Systems for Multistory Buildings, Pacific Earthquake 500 Engineering Research Center, College of Engineering, University of California, Berkeley.

501 Ibarra, L. F., Medina, R. A., and Krawinkler, H. (2005). "Hysteretic models that incorporate strength 502 and stiffness deterioration." Earthq Eng Struct D, 34(12), 1489-1511.

503 Iervolino, I., Galasso, C., and Cosenza, E. (2010). "REXEL: computer aided record selection for 504 code-based seismic structural analysis." Bull. Earthq. Eng., 8(2), 339-362.

505 Magliulo, G., Ercolino, M., and Manfredi, G. (2015). "Influence of cladding panels on the first 506 period of one-story precast buildings." Bulletin of Earthquake Engineering, 13(5), 1531-1555. 
507 Magliulo, G., Ercolino, M., Petrone, C., Coppola, O., and Manfredi, G. (2014). "The Emilia

508 Earthquake: Seismic Performance of Precast Reinforced Concrete Buildings." Earthq Spectra, $50930(2), 891-912$.

510 Mander, J. B., Priestley, M. J. N., and Park, R. (1988). "Theoretical Stress-Strain Model for 511 Confined Concrete." J. Struct. Eng.-Asce, 114(8), 1804-1826.

512 McKenna, F., and Fenves, G. (2013). "OpenSees Manual http://opensees.berkeley.edu." Pacific 513 Earthquake Engineering Research Center.

514 PEER (2006). "PEER NGA Database http://peer.berkeley.edu/nga/." PEER Center, College of 515 Engineering, University of California.

516 Talaat, M., and Mosalam, K. M. (2009). "Modeling progressive collapse in reinforced concrete 517 buildings using direct element removal." Earthquake Eng Struc, 38(5), 609-634.

518 Vamvatsikos, D. "Incremental dynamic analysis with two components of motion for a 3D steel 519 structure." Proc., 10th International Conference on Applications of Statistics and Probability in 520 Civil Engineering,Tokyo.

521 Vamvatsikos, D., and Cornell, C. A. (2002). "Incremental dynamic analysis." Earthq Eng Struct D, $522 \quad 31(3), 491-514$.

523 Wen, Y., and Song, S. (2003). "Structural Reliability/Redundancy under Earthquakes." Journal of 524 Structural Engineering, 129(1), 56-67.

525 Zoubek, B., Fischinger, M., and Isaković, T. (2016). "Cyclic response of hammer-head strap 526 cladding-to-structure connections used in RC precast building." Engineering Structures, 119, 135527148. 
Table 1 Fundamental periods of the six structural models [sec]

531

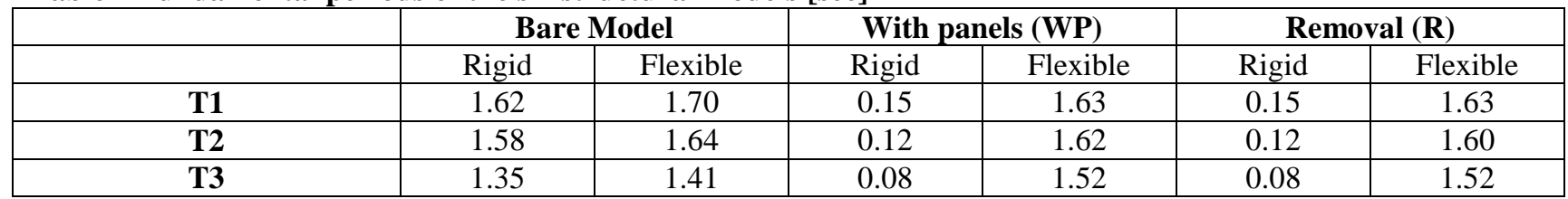

532 
Table 2 Features of the selected seismic events

\begin{tabular}{|c|c|c|c|c|c|c|}
\hline ID & Earthquake Name & Date & $\mathbf{M}_{\mathbf{w}}$ & $\mathbf{P G A}_{\mathbf{x}}[\mathbf{g}]$ & $\mathbf{P G A}_{\mathbf{y}}\left[\mathbf{m} / \mathbf{s}^{2}\right]$ & \multicolumn{1}{|c|}{ EC8 Site class } \\
\hline $\mathbf{1 3 4}$ & Friuli (aftershock) & $15 / 09 / 1976$ & 6.0 & 0.25 & 0.21 & \\
\hline $\mathbf{1 4 7}$ & Friuli (aftershock) & $15 / 09 / 1976$ & 6.0 & 0.13 & 023 & \\
\hline $\mathbf{1 9 6}$ & Montenegro & $09 / 04 / 1979$ & 6.9 & 0.44 & 0.29 & \multirow{2}{*}{ B } \\
\hline $\mathbf{2 3 1}$ & Montenegro (aftershock) & $24 / 05 / 1979$ & 6.2 & 0.16 & 0.13 & \\
\hline $\mathbf{2 9 1}$ & Campano Lucano & $23 / 11 / 1980$ & 6.9 & 0.15 & 0.17 & \\
\hline $\mathbf{5 3 5}$ & Erzincan & $13 / 03 / 1992$ & 6.6 & 0.38 & 0.50 & \\
\hline $\mathbf{1 7 1 4}$ & Ano Liosia & $07 / 09 / 1999$ & 6.0 & 0.23 & 0.21 & \\
\hline
\end{tabular}


536 Table 3 Overview of the adopted structural models

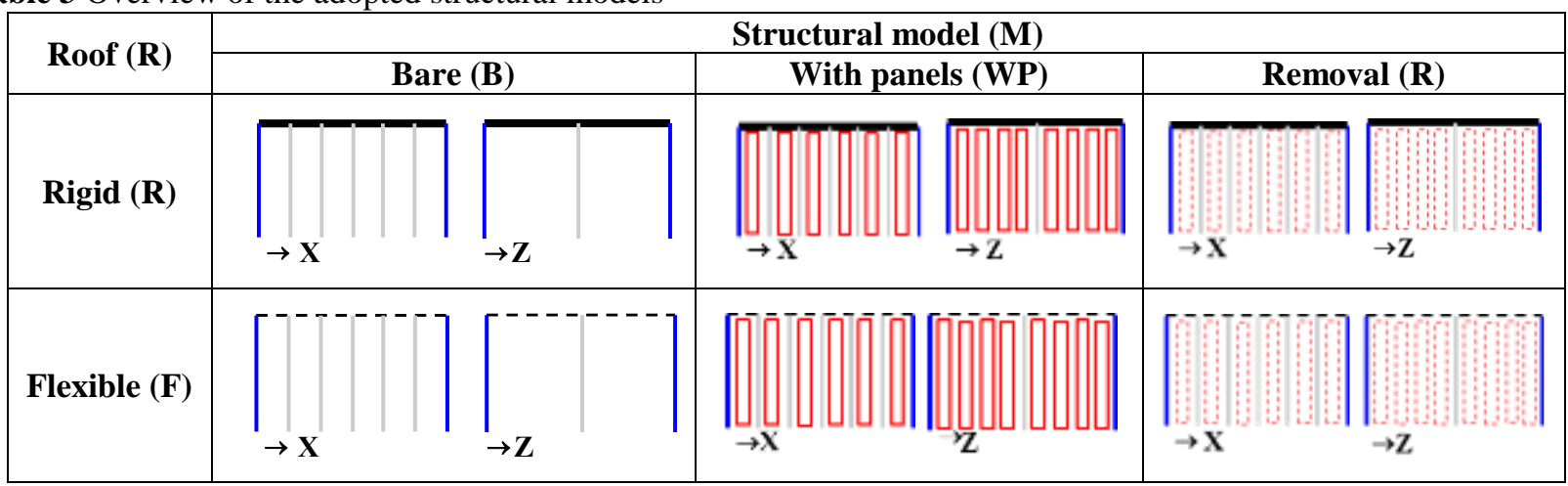

